\title{
INTEGRASI PERPUSTAKAAN DAN KURIKULUM BERBASIS RISET UNTUK MENINGKATKAN NILAI INDEKS PRESTASI MAHASISWA-SANTRI PONDOK PESANTREN UNIVERSITAS ISLAM INDONESIA
}

\author{
Imam Sahroni
}

Penelitian ini bertujuan untuk mengetahui pengaruh hadirnya fasilitas perpustakaan terhadap nilai Indeks Prestasi (IP) mahasiswa di Pondok Pesantren Universitas Islam Indonesia (UII) pada pergantian tahun akademik, yaitu semester genap 2011/2012 dan semester ganjil 2012/2013. Dalam hal ini juga dapat dilihat efektivitas program integrasi perpustakaan dengan kurikulum berbasis riset guna mendukung peningkatan nilai indeks prestasi mahasiswa dan misi perguruan tinggi menjadi World Class University (WCU). Data primer diambil dari mahasiswa-santri Pondok Pesantren Universitas Islam Indosia (UII) angkatan 2009 (12 mahasiswa), 2010 (10 mahasiswa), dan 2011 (12 mahasiswa). Dari analisa data didapatkan hasil persentase kenaikan prestasi akademik mahasiswa-santri Pondok Pesantren UIl angkatan 2009 (12 mahasiswa) mengalami kenaikan nilai Indeks Prestasi sebanyak 75 \% (9 mahasiswa) dan 25 \% (3 mahasiswa) mengalami penurunan. Untuk angkatan 2010 mengalami kenaikan nilai Indeks Prestasi sebanyak 70 \% (7 mahasiswa) dan penurunan 30 \% (3 mahasiswa). Untuk angkatan 2011 mengalami peningkatan nilai Indeks Prestasi sebanyak $52 \%$ (7 mahasiswa) dan penurunan $42 \%$ (5 mahasiswa).

Kata kunci: perpustakaan, kurikulum riset, indeks prestasi,

\section{Pendahuluan}

Beberapa tahun terakhir ini, perguruan tinggi negeri maupun swasta sedang gencar berupaya untuk menjadi universitas kelas dunia/ World Class University (WCU). Dalam hal ini, Dirjen Dikti menyatakan mendukung penuh perguruan tinggi agar dapat menjadi berkelas internasional. Dengan adanya regulasi ini, otomatis setiap perguruan tinggi saling berlomba untuk memperbaiki sistem pendidikan, baik dari level kurikulum, keseharian mahasiswa, dan kebijakan perguruan tinggi.

Di level kurikulum dipahami sebagai seperangkat rencana yang memberi pedoman atau pegangan dalam proses kegiatan belajar mengajar (Susilo, 2008: 80). Kurikulum juga merupakan terjemahan dari visi dan misi sebuah lembaga pendidikan. Dengan adanya kurikulum, maka visi dan misi akan mudah diraih.

Salah satu komponen terpenting pada lembaga pendidikan formal pada level kurikulum yang digunakan sebagai fasilitas pendukung dalam kegiatan belajar, mengarahkan proses mekanisme pendidikan, tolok ukur keberhasilan dan kualitas hasil pendidikan adalah perpustakaan (Nasution, 1995: 13).

Perpustakaanmemilikiperansangatpenting dan strategis sebagai partner dalam mendukung tujuan nasional, yaitu mencerdaskan kehidupan bangsa. Pengembangan perpustakaan menuju digital library sebenarnya bukan sekadar menyesuaikan dengan perkembangan teknologi informasi, tetapi lebih karena tuntutan adanya perubahan paradigma perguruan tinggi, yang mencakup adanya perubahan paradigma dalam pembelajaran dengan e-learning, perubahan dalam komunikasi ilmiah yang mengarah kepada e-research, serta kebutuhan mendesak untuk menciptakan information literacy di perguruan tinggi.

Dengan perkembangan e-learning maka akan muncul tuntutan untuk sebuah jasa pelayanan informasi digital yang terintegrasi dengan sistem belajar mengajar. Teknologi digital dewasa ini telah menawarkan berbagai 
kemungkinan penggabungan antara kelas, laboraturium, perpustakaan, dan bahkan museum. Lebih jauh integrasi ini kemudian menghasilkan sebuah sistem pendidikan yang berbasis perpustakaan (library-base education) (Rodliyah, 2012).

Salah satu lembaga formal yang mengaitkan sistem pedidikan berdasarkan kurikulum dengan perpustakaan adalah Pondok Pesantren Universitas Islam Indonesia (UII). Pondok Pesantren UII merupakan lembaga pendidikan formal dari UII yang diperuntukkan khusus bagi mahasiswa-mahasiswa yang mendapatkan beasiswa Santri Unggulan berdasarkan seleksi yang telah disyahkan oleh Dewan Taujih Universitas Islam Indonesia.

Pengembangan kurikulum pondok pesantren UII didasarkan pada prinsip tujuan dan prinsip relevansi. Kurikulum Pondok Pesantren UII didesain guna menyesuaikan dengan tujuan dengan melihat kondisi zaman yang menuntut adanya perubahan pada kurikulum. Sejak berdiri padatahun 1996 hingga saatini, kurikulum pondok pesantren telah mengalami tiga kali perubahan. Kurikulum 1996 dan 2003 menekankan pada kemampuan akademis, dakwah dan mencetak para mujtahid. Sedangkan kurikulum 2010 para santri lebih diarahkan pada kemampuan nalar analisis, dakwah, dan mahir dalam menuliskan karya ilmiah serta penelitian. Desain kurikulum tersebut disesuaikan dengan misi Universitas Islam Indonesia menjadi World Class University (WCU).

Guna menunjang kebutuhan-kebutuhan yang diperlukan kurikulum baru yang berbasis penelitian tersebut, maka berdirilah fasilitas yang berupa perpustakaan di Pondok Pesantren UII. Perpustkaan PPUII ini tepatnya diresmikan oleh Rektor UII, Prof. Edy Suandi Hamid, M. Sc pada tahun ajaran 2012/2013 tepatnya pada tanggal 26 Januari 2012 (Aziz, 2013).

Dalam hal penelitian ini penulis bertujuan untuk melihat pengaruh perpustakaan di Pondok Pesantren UII terhadap nilai Indeks Prestasi (IP) mahasiswa (sebelum dan sesudah adanya perpustakaan). Lebih jauh lagi penulis juga melihat efektivitas dan efisiensi perpustakaan apabila diintegrasikan dengan kurikulum berbasisis riset dalam hal mendukung misi perguruan tinggi menjadi World Class University (WCU).

\section{Perumusan Masalah}

Berdasarkan latar belakang dan uraian tersebut diatas, maka dapat dirumuskan suatu permasalahan sebagai berikut:

1. Apa pengaruh hadirnya perpustakaan terhadap nilai Indeks Prestasi (IP) pada semester ganjil dan genap Mahasiswa Pondok Pesantren UII?

2. Bagaimana efektivitas dan efisiensi perpustakaan apabila diintegrasikan dengan kurikulum berbasis riset guna meningkatkan kualitas prestasi akademik Mahasiswa Pondok Pesantren UII ?

\section{Tujuan}

Berdasarkan rincian masalah di atas, maka penelitian ini dilakukan dengan tujuan sebagai berikut:

1. Mengetahui pengaruh adanya fasilitas perpustakaan terhadap nilai Indeks Prestasi (IP) Mahasiswa Pondok Pesantren UII.

2. Mengetahui efektivitas dan efisiensi perpustakaan apabila diintegrasikan dengan kurikulum berbasisis riset guna meningkatkan kualitas prestasi akademik Mahasiswa Pondok Pesantren UII.

\section{Manfaat}

Keberhasilan dari penelitian ini akan membawa manfaat bagi:

1. Peningkatan prestasi akademik bagi seluruh mahasiswa di Indonesia dari berbagai sisi antara lain melaui pengoptimalan fasilitas perpustakaan guna mendukung program Perguruan tinggi (PT) menjadi kampus dengan status World Class University (WCU),

2. Peningkatan daya nalar dan inovasi mahasiswa: adanya integrasi perpustakaan dan kurikulum yang berbasis pada kegiatan riset membuat mahasiswa lebih kreatif dan inovatif dalam melakukan inovasi,

3. Peningkatan kualitas dan prestasi Perguruan tinggi (PT): peningkatan nilai akademik mahasiswa akan mendukung universitas dalam peningkatan nilai akreditasi dan mendukung misi menjadi world class research university. 
Faktor-Faktor yang Memengaruhi Proses dan Hasil Belajar

Menurut Suryabrata (1989 dalam Yuniah 2006), dalam proses belajar-mengajar ikut berpengaruh sejumlah faktor yang berinteraksi satu sama lain dalam menentukan proses dan hasil belajar, baik faktor dari dalam, yaitu keadaan fisiologis (kesehatan, kondisi panca indera, dan kecukupan gizi), serta keadaan psikologis (minat, kecerdasan, motivasi, dan kemampuan kognitif), maupun faktor dari luar yang terdiri dari input lingkungan dan input instrumental. Input lingkungan berupa lingkungan sosial serta lingkungan alami (keadaan suhu dan kelembaban udara). Input instrumental adalah sejumlah faktor yang dengan sengaja dirancangkan dan dimanipulasi guna menunjang tercapainya output yang dikehendaki, yaitu berupa kurikulum, program, sarana, fasilitas, dan tenaga pengajar.

\section{Prestasi Akademik}

Pengertian prestasi akademik adalah hasil pelajaran yang diperoleh dari kegiatan belajar di sekolah atau perguruan tinggi yang bersifat kognitif dan biasanya ditentukan melalui pengukuran dan penilaian. Prestasi akademik pada penelitian ini dinilai berdasarkan IPS (Indeks Prestasi Semester).

Indeks Prestasi (IP) adalah penilaian keberhasilan studi semester yang dilakukan pada tiap akhir semestar (Universitas Islam Indonesia tahun ajaran 2011/2012 dan 2012/2013). Penilaian ini meliputi semua mata kuliah yang direncanakan mahasiswa dalam Kartu Rencana Studi (KRS).

\section{Indeks Prestasi}

Penilaian keberhasilan studi mahasiswa Pondok Pesantren Universitas Islam Indonesia pada akhir tahun akademik dihitung dengan rumus Indeks Prestasi (IP) sebagai berikut :

$$
\mathrm{IP}=\frac{\sum_{i=1}^{n} N_{i} k_{i}}{\sum_{i=1}^{n} k_{i}}
$$

Keterangan :

IP = Indeks Prestasi

$\mathrm{N}_{\mathrm{i}}=$ Nilai mutu mata kuliah $\mathrm{i}$

$\mathrm{K}_{\mathrm{i}}=$ Bobot sks mata kuliah $\mathrm{i}$

$\mathrm{n}=$ Jumlah mata kuliah

\section{Predikat Kelulusan}

Predikat kelulusan merupakan penghargaan akademik atas prestasi yang diperoleh seorang mahasiswa selama mengikuti perkuliahan tahun akademik 2011/2012 dan 2012/2013 (Mahasiswa-Santri Pondok Pesantren UII). Predikat kelulusan beserta ketentuannya dapat dilihat pada Tabel 1.

Tabel 1. Predikat kelulusan hasil penilaian akhir belajar (Sumber: Yuniah, 2006)

\begin{tabular}{|l|l|l|}
\hline No. & $\begin{array}{c}\text { Indeks Prestasi } \\
\text { Semester }\end{array}$ & \multicolumn{1}{|c|}{ Ketentuan } \\
\hline 1. & IP $\geq 3,51$ & $\begin{array}{l}\text { Tanpa nilai D dan E, } \\
\text { hanya 1 nilai C diluar } \\
\text { mata kuliah wajib }\end{array}$ \\
\hline 2. & $\begin{array}{l}\text { IP } \geq 3,51 \\
2,76 \leq I P<3,51\end{array}$ & $\begin{array}{l}\text { Tidak memenuhi } \\
\text { butir } 1 \text {, tanpa nilai D }\end{array}$ \\
\hline 3. & $\begin{array}{l}2,76 \leq \mathrm{IP}<3,51 \\
2,0 \leq \mathrm{IP}<2,76\end{array}$ & $\begin{array}{l}\text { Tidak memenuhi } \\
\text { butir } 1 \text { dan 2 }\end{array}$ \\
\hline 4. & $\mathrm{IP}<2,0$ & $\begin{array}{l}\text { Tidak memenuhi } \\
\text { butir } 1,2, \text { dan 3 }\end{array}$ \\
\hline
\end{tabular}

\section{Perpustakaan Berbasis Pendidikan (Libary- Base Education)}

Berbagai hal yang mendorong lahirnya perpustakaan berbasis pendidikan antara lain adalah untuk memudahkan penelusuran informasi. Dengan tersedianya full-text database memungkinkan menelusur dengan menggunakan kata kunci dari kata yang tersedia. Koleksi tidak pernah habis dipakai. Dalam bentuk digital, copy dari data tetap sebaik dan seoriginal bentuk aslinya. Koleksi digital selalu siap kapanpun pemustaka membutuhkan tidak ada kata Off-self berapapun banyak pemakainya. (Pudjiono, 2006).

Beberapa keuntungan konkret yang didapatkan dari integrasi ini adalah :

1. Membangun citra perpustakaan kepada publik. Dengan citra yang baik, ketertarikan pengunjung akan meningkat. 
2. Kemudahan membangun jaringan. Jaringan yang luas sangat penting bagi perkembangan perpustakaan. Dengan adanya jaringan antar perpustakaan, maka akan memberi keuntungan kepada dua pihak, yaitu pemustaka dan perpustakaan. Para pengguna jasa perpustakaan akan lebih mudah mendapatkan informasi dari berbagai perpustakaan yang terhubung dalam jaringan tersebut. Sedangkan pihak perpustakaan mendapatkan keuntungan dengan adanya transfer informasi perpustakaan.

\section{Metode Penelitian}

\section{Bahan}

Penelitian ini menggunakan data primer, data Indeks Prestasi (IP) semester mahasiswa Pondok Pesantren UII angkatan 2009 (12 mahasiswa), 2010 (10 mahasiswa), dan 2011 (12 mahasiswa) tahun ajaran 2011/2012 dan 2012/2013. Data Indeks Prestasi masing-masing mahasiwa diperoleh dari akun uniysis.uii.ac.id.

Tahapan pengumpulan data yang dilakukan dalam penelitian ini adalah sebagai berikut:

1. Persiapan data IP semester

Persiapan yang dilakukan adalah mencari informasi tentang mahasiswa PP UII angkatan 2009, 2010, dan 2011, kondisi perpustakaan PP UII dan melihat detail kurikulum riset yang diterapkan pada proses pembelajaran di PP UII.

2. Analisis data

Analisis data dari hasil informasi Indeks Prestasi per semester yang telah penulis himpun, selanjutnya diolah menggunakan microsoft excel.

\section{Metode}

Langkah-langkah analisis data dalam penelitian ini adalah sebagai berikut:

1. Analisis persentase kenaikan atau penurunan IP

Dari data IP semester masing-masing mahasiswa PP UII tahun ajaran 2011/2012 dan 2012/2013, maka dapat ditentukan persentase (\%) kenaikan atau penurunan
IP masing-masing mahasiswa dengan menggunakan rumus :

$$
=\frac{\left(\text { IP t. a } \frac{2012}{2013}\right)-\left(\text { IP t. a } \frac{2011}{2012}\right)}{\left(\text { IP t. a } \frac{2012}{2013}\right)} \times 100 \%
$$

Dimana: IP t.a 2012/2013 merupakan PP UIl sudah ada fasilitas perpustakaan IP t.a 2011/2012 merupakan PP UII belum ada fasilitas perpustakaan

2. Menganalisa faktor-faktor yang berpengaruh terhadap prestasi akademik mahasiswa PP UII

3. Menganalisa tingkat integrasi perpustakaan dengan kurikulum berbasis riset dalam hal peningkatan prestasi akademik mahasiswa PP UII.

\section{Pembahasan}

\section{Deskripsi Analisa Indeks Prestasi}

Dari 34 mahasiswa yang dianalisis, secara umum prestasi akademik mahasiswa Pondok Pesantren UII angkatan 2009 (12 mahasiswa), 2010 (10 mahasiswa), dan 2011 (12 mahasiswa) mengalami kenaikan drastis setelah adanya perpustakaan yang diintegrasikan dengan kurikulum berbasis riset. Tabel 1 dan tabel 2 menunjukkan selisih jumlah kenaikan atau penurunan nilai Indeks Prestasi mahasiswasantri Pondok Pesantren UII angkatan 2009.

Tabel 2. Nilai Indeks Prestasi mahasiswa-santri angkatan 2009

Nilai IP Semester 2011/2012 \& 2012/2013

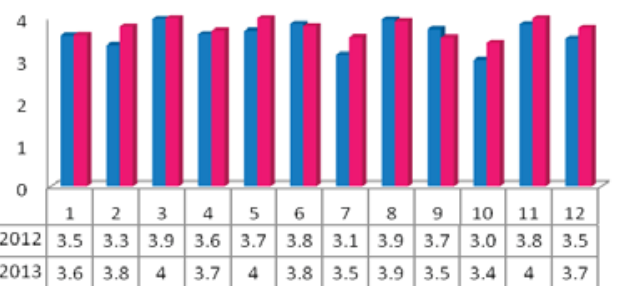

Tabel 3. Persentase Kenaikan nilai IP angkatan 2009

\begin{tabular}{|c|l|r|r|r|}
\hline No. & \multicolumn{1}{|c|}{$\begin{array}{c}\text { Nama } \\
\text { Mahasiswa }\end{array}$} & \multicolumn{1}{|c|}{$\begin{array}{c}\text { IP } \\
\text { Genap }\end{array}$} & $\begin{array}{c}\text { IP } \\
\text { Ganjil }\end{array}$ & $\begin{array}{c}\text { Persen } \\
\text { Kenaikan } \\
(\%)\end{array}$ \\
\hline 1 & $\begin{array}{l}\text { Achmad } \\
\text { Nurdany }\end{array}$ & 3,59 & 3,6 & 0,277778 \\
\hline 2 & Ady Guswadi & 3,36 & 3,8 & 11,57895 \\
\hline 3 & $\begin{array}{l}\text { Ahmad Zaini } \\
\text { Aziz }\end{array}$ & 3,98 & 4 & 0,502513 \\
\hline
\end{tabular}




\begin{tabular}{|c|l|r|r|r|}
\hline 4 & $\begin{array}{l}\text { Ahmadi } \\
\text { Hasanuddin } \\
\text { Dardiri }\end{array}$ & 3,62 & 3,7 & 2,162162 \\
\hline 5 & Amir Hamzah & 3,7 & 4 & 7,5 \\
\hline 6 & $\begin{array}{l}\text { M. Miqdam } \\
\text { Musawwa }\end{array}$ & 3,87 & 3,81 & $-1,5748$ \\
\hline 7 & $\begin{array}{l}\text { M Khairul } \\
\text { Ansor }\end{array}$ & 3,13 & 3,55 & 11,83099 \\
\hline 8 & $\begin{array}{l}\text { Yasser Azka } \\
\text { Ulil Albab }\end{array}$ & 3,97 & 3,93 & $-1,01781$ \\
\hline 9 & $\begin{array}{l}\text { Samsul } \\
\text { Zakaria }\end{array}$ & 3,74 & 3,54 & $-5,64972$ \\
\hline 10 & Syahruddin & 3,01 & 3,41 & 11,73021 \\
\hline 11 & $\begin{array}{l}\text { Syaifulloh } \\
\text { Yusuf }\end{array}$ & 3,86 & 4 & 3,5 \\
\hline 12 & $\begin{array}{l}\text { Tubagus } \\
\text { Sukron } \\
\text { Tamimi }\end{array}$ & 3,52 & 3,77 & 6,6313 \\
\hline
\end{tabular}

\begin{tabular}{|l|l|l|l|l|}
\hline 5 & Fadhal Fajri & 3,65 & 3,61 & $-1,10803$ \\
\hline 6 & Imam Sahroni & 3,16 & 3,54 & 10,73446 \\
\hline 7 & Miftahul Ulum & 3,59 & 3,53 & $-1,69972$ \\
\hline 8 & $\begin{array}{l}\text { M. Iqbal } \\
\text { Juliansyah } \\
\text { Zen }\end{array}$ & 3,88 & 3,92 & 1,020408 \\
\hline 9 & $\begin{array}{l}\text { Muhammad } \\
\text { Qomaruddin }\end{array}$ & 3,96 & 3,8 & $-4,21053$ \\
\hline 10 & Priyo Sudibyo & 3,47 & 3,98 & 12,81407 \\
\hline
\end{tabular}

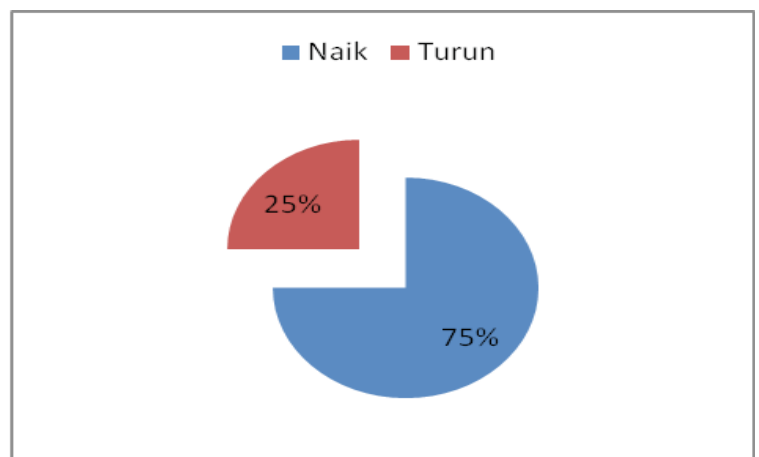

Grafik1. Persentase prestasi akademik mahasiswa-santri PP UII angkatan 2009

Tabel 4. Nilai Indeks Prestasi mahasiswa-santri angkatan 2010

\section{Nilai IP Semester 2011/2012 \& 2012/2013}

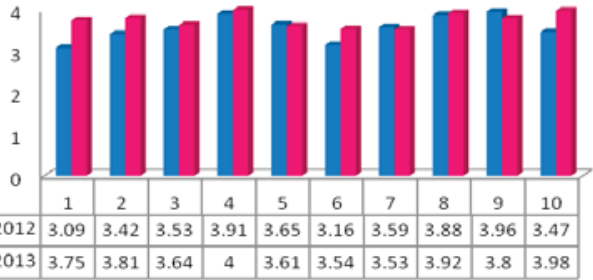

\begin{tabular}{|l|l|l|l|l|l|l|l|l|l|l|}
\hline IP 2012/2013 & 3.75 & 3.81 & 3.64 & 4 & 3.61 & 3.54 & 3.53 & 3.92 & 3.8 & 3.98 \\
\hline
\end{tabular}

Tabel 5. Persentase Kenaikan nilai IP angkatan 2010

\begin{tabular}{|l|l|l|l|l|}
\hline No. & \multicolumn{1}{|c|}{$\begin{array}{c}\text { Nama } \\
\text { Mahasiswa }\end{array}$} & $\begin{array}{c}\text { IP } \\
\text { Genap }\end{array}$ & $\begin{array}{c}\text { IP } \\
\text { Ganjil }\end{array}$ & $\begin{array}{c}\text { Persen } \\
\text { Kenaikan } \\
(\%)\end{array}$ \\
\hline 1 & $\begin{array}{l}\text { Muh. Irham } \\
\text { Roihan }\end{array}$ & 3,09 & 3,75 & 17,6 \\
\hline 2 & Suharyanto & 3,42 & 3,81 & 10,23622 \\
\hline 3 & Ahmad Said & 3,53 & 3,64 & 3,021978 \\
\hline 4 & $\begin{array}{l}\text { Ardy Bustomi } \\
\text { Kurniawan }\end{array}$ & 3,91 & 4 & 2,25 \\
\hline
\end{tabular}

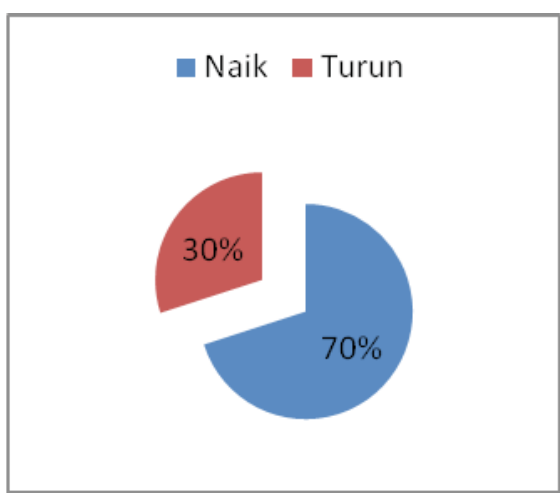

Grafik 2. Persentase prestasi akademik mahasiswa-santri PP UII angkatan 2010

Tabel 6. Nilai Indeks Prestasi mahasiswa-santri angkatan 2011

\section{Nilai IP Semester 2011/2012 \& 2012/2013}

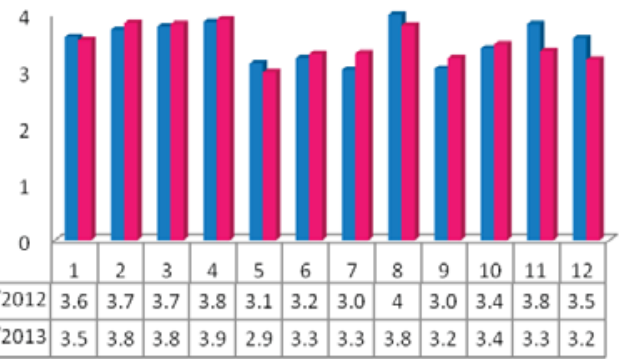

Tabel 7. Persentase Kenaikan nilai IP angkatan 2011

\begin{tabular}{|c|l|l|l|l|}
\hline No. & \multicolumn{1}{|c|}{$\begin{array}{c}\text { Nama } \\
\text { Mahasiswa }\end{array}$} & $\begin{array}{c}\text { IP } \\
\text { Genap }\end{array}$ & $\begin{array}{c}\text { IP } \\
\text { Ganjil }\end{array}$ & $\begin{array}{c}\text { Persen } \\
\text { Kenaikan } \\
(\%)\end{array}$ \\
\hline 1 & Ahmad Azizi & 3,16 & 3,54 & $-1,69492$ \\
\hline 2 & Amin Nurridha & 3,73 & 3,85 & 3,116883 \\
\hline 3 & $\begin{array}{l}\text { M. Arsyad } \\
\text { Haikal }\end{array}$ & 3,79 & 3,83 & 1,044386 \\
\hline 4 & Mohammad Ali & 3,87 & 3,91 & 1,023018 \\
\hline 5 & Hairul Umam B & 3,13 & 2,97 & $-5,38721$ \\
\hline 6 & $\begin{array}{l}\text { Ahmad } \\
\text { Musaddad }\end{array}$ & 3,23 & 3,3 & 2,121212 \\
\hline 7 & $\begin{array}{l}\text { Musain } \\
\text { Syaifusief }\end{array}$ & 3,02 & 3,31 & 8,761329 \\
\hline
\end{tabular}


Integrasi Perpustakaan dan Kurikulum ...(Imam Sahroni)

\begin{tabular}{|c|l|l|l|l|}
\hline 8 & $\begin{array}{l}\text { Khulafaur } \\
\text { Rosidin }\end{array}$ & 4 & 3,81 & $-4,98688$ \\
\hline 9 & Yevi Yusnanda & 3,04 & 3,23 & 5,882353 \\
\hline 10 & Hanif Rahmat & 3,4 & 3,47 & 2,017291 \\
\hline 11 & $\begin{array}{l}\text { Muhammad } \\
\text { Yasin Al-arif }\end{array}$ & 3,83 & 3,35 & $-14,3284$ \\
\hline 12 & $\begin{array}{l}\text { Ahmad Rijalul } \\
\text { Dzikri }\end{array}$ & 3,58 & 3,2 & $-11,875$ \\
\hline
\end{tabular}

7 mahasiswa yang mengalami kenaikan nilai Indeks Prestasi dan 3 lainnya mengalami penurunan, sedangkan untuk angkatan 2011 ada 7 mahasiswa yang mengalami kenaikan, sedangkan 5 lainnya mengalami penurunan. Dari hasil tersebut dapat dipahami bahwa integrasi perpustakaan dengan kurikulum berbasis riset terbukti efektif dan efisien dalam meningkatkan prestasi akademik mahasiswa.

\section{Saran}

Berdasarkan hasil analisis data dan kesimpulan di atas, maka peneliti memberikan saran antara lain:

1. Kepada mahasiswa-santri Pondok Pesantren UII lebih mengoptimalkan lagi fasilitas perpustakaan yang telah disediakan sebagai penunjang kegiatan belajar di lingkungan kampus Universitas Islam Indonesia.

kenaikan prestasi akademik mahasiswa-santri Pondok Pesantren UII angkatan 2009 (12 mahasiswa) mengalami kenaikan nilai Indeks Prestasi sebanyak $75 \%$ (9 mahasiswa) dan $25 \%$ (3 mahasiswa) mengalami penurunan. Untuk angkatan 2010 mengalami kenaikan nilai Indeks Prestasi sebanyak 70 \% (7 mahasiswa) dan penurunan $30 \%$ (3 mahasiswa). Untuk angkatan 2011 mengalami peningkatan nilai Indeks Prestasi sebanyak 52 \% (7 mahasiswa) dan penurunan $42 \%$ (5 mahasiswa).

\section{Kesimpulan}

Berdasarkan hasil penelitian yang telah dipaparkan dalam pembahasan di atas, maka peneliti dapat mengambil kesimpulan sebagai berikut:

1. Hadirnya perpustakaan sebagai media pendukung terhadap kegiatan belajar mahasiswa di Pondok Pesantren UII dapat meningkatkan nilai Indeks Prestasi pada tahun akademik 2012/2013. Angakatan 2009 naik $75 \%$, angkatan 2010 naik $70 \%$, dan angkatan 2011 naik $52 \%$.

2. Integrasi perpustakaan dengan kurikulum berbasis riset dapat meningkatkan kualitas prestasi akademik Mahasiswa Pondok Pesantren UII. Dari 12 mahasiswa angkatan 2009 ada 9 mahasiswa yang nilai Indeks Prestasinya naik, dan hanya 3 mahasiswa yang turun. Angkatan 2010 ada

2. Kepada pengelola perpustakaan agar dapat mengembangkan lagi program integrasi perpustakaan dengan kurikulum berbasis riset karena terbukti dapat meningkatkan prestasi akademik mayoritas mahasiswa Pondok Pesantren UII.

\section{Daftar Pustaka}

Aziz, Zaini Ahmad. 2013. Analisis SWOT pada Kurikulum Pondok Pesantren Universitas Islam Indonesia. Skripsi. Yogyakarta: Program Studi Pendidikan Agama Islam FIAI UII.

Pudjiono. 2006. Membangun Citra: Perpustakaan Perguruan Tinggi di Indonesia Menuju Perpustakaan Bertaraf Internasional. http:// www.lib.ui.ac.id/files/Pudjiono.pdf

Nasution S.. 1995. Asas-asas Kurikulum. Jakarta: Bumi Aksara

Rodliyah, Umi. 2012. Perpustakaan Digital, dan Prospeknya Menuju Resource Sharing. Visita Pustaka. Vol. 14, No. 1, 39-47

Susilo, Muhammad Joko. 2008. Kurikulum Tingkat Satuan Pendidikan. Yogyakarta: Pustaka Pelajar

Yuniah. 2006. Faktor-faktor yang Berpengaruh Terhadap Prestasi Akademik Mahasiswa TPB IPB dengan Metode Chaid (Skripsi). Bogor: Jurusan Statistikan FMIPA IPB 